\title{
Computerised psychiatric case registers in Britain
}

\author{
STEPHEN Wood, Senior Lecturer, United Medical \& Dental Schools, Academic \\ Psychiatry Unit, St Martin's Hospital, Canterbury CT1 1TD; MARTIN ElPHICK, \\ Consultant Psychiatrist, Fair Mile Hospital, Cholsey, Oxfordshire OX10 9HH; and \\ Mike SinClaIR, Mental Health Information Technology Department, Guy's \\ Hospital, London SE1 9RT
}

Case registers can provide useful data for research and service planning, but the older manually maintained registers were expensive and required special accommodation, staffing and support. Turning raw data into useful information was a laborious process and most systems could not accommodate ad hoc reports. Partly as a result of these shortcomings, and partly because of spending cuts, a number of case registers were closed in the 1980s (for example, see Hassall, 1991).

In the past five or six years desk-top microcomputers have become more widely used in health care settings. Many were purchased as word processors, but can also be used for other purposes including databases and spreadsheets, and from such general applications automated case registers can be developed. At the same time, some hospitals have installed more ambitious computer systems to provide financial and management information, and as familiarity has grown, clinical applications have sometimes been developed.

The growth of interest in assertive outreach services for patients with chronic severe psychiatric illness (Clifford et al, 1988), the consequences of patients 'falling through the cracks' of community care (DHSS, 1988) and legislation on care plans incorporated in the NHS and Community Care Act (1991), have all given added impetus to the development of computerised registers. In spite of the growth of interest in case registers, the psychiatric literature has not kept pace and clinicians and managers contemplating a purchase may have nothing more objective than promotional material upon which to base their choice.

The present survey describes the characteristics of the computerised psychiatric case registers known to us by mid 1991. Although we believe that we have gathered our data widely through pesonal contacts and the Computers in Psychiatry Special Interest Group of the College, the information is inevitably incomplete. We hope that the aggrieved owners and developers of systems which we have overlooked will forgive our oversight and provide details for inclusion in subsequent surveys. The full text of the survey is to be published by the NHS Management Executive.

\section{The study}

No attempt was made to form a judgement on the relative merits of the systems which we reviewed, but rather to record their attributes as objectively as possible.

Systems were included if they satisfied the following criteria.

(a) The system should facilitate clinical management by the electronic storage, manipulation and retrieval of patient data. Systems providing only management or clinical activity data were excluded, as were those used solely for research purposes.

(b) Systems should maintain personal data as defined by the Data Protection Act (1983), and would be expected to require registration.

(c) The system should be operational at one or more sites.

(d) The system and software should be distinctively different from similar systems.

Developers were asked to provide details outlined in Table I.

Most systems were personally inspected by one or more of the authors, and their comments incorporated into the data provided by the system developers.

\section{Findings}

\section{Distribution}

Twenty-one systems were located at 43 sites, 39 of which were in England. The greatest concentration was in the Thames Regions (20) with 19 elsewhere in England, three in Scotland and one in Ireland. None were located in Wales or Northern Ireland.

Table II lists the systems reviewed and the main sites at which they were located. 
TABLE I.

Information collected

Brief description of system

History and development

Name and address of contact

Methods of data input (keyboard/mouse etc)

Structure and type of data supported

Data reporting (reports/graphics/statistics)

On-line help

Data security

Backup methods (floppy disk/tape streamer etc)

Hardware requirements

Software requirements, including operating system

Interfacing ability (e.g. to PAS)

Maintenance and support requirements

Personnel and training requirements

Costs

References

\section{Development and scope}

Two thirds (14) of the systems were relatively simple in concept and had been developed by clinicians to assist in the work of community teams, wards and other services. They had usually been programmed by the clinicians themselves, sometimes with assistance from health authorities or university departments.

Only five of the 21 systems were commercial developments. These systems-CRISP, CRAMS, and the systems operating in Bradford, Edinburgh and Napsbury - were more ambitious in concept and cost considerably more to implement but were comprehensive information systems which could fulfil the needs of groups of hospitals or even entire districts.

Two other systems, at Guy's and St Bernard's Hospitals, although developed 'in-house' were also comprehensive in scope, using networks of interconnected computers distributed over several sites.

Most of the systems were intended for general use in adult psychiatry but three were for use in forensic units, three in child psychiatry and one in psychogeriatrics. Four more were specifically designed for the care of the long-term mentally ill in the community. One specialised system was intended for monitoring of lithium and depot antipsychotic drugs.

\section{Hardware requirements}

All but two used IBM compatible microcomputers, usually faster machines based on 80286 or 80386

TABLE 11.

Systems received and main sites at which they were located

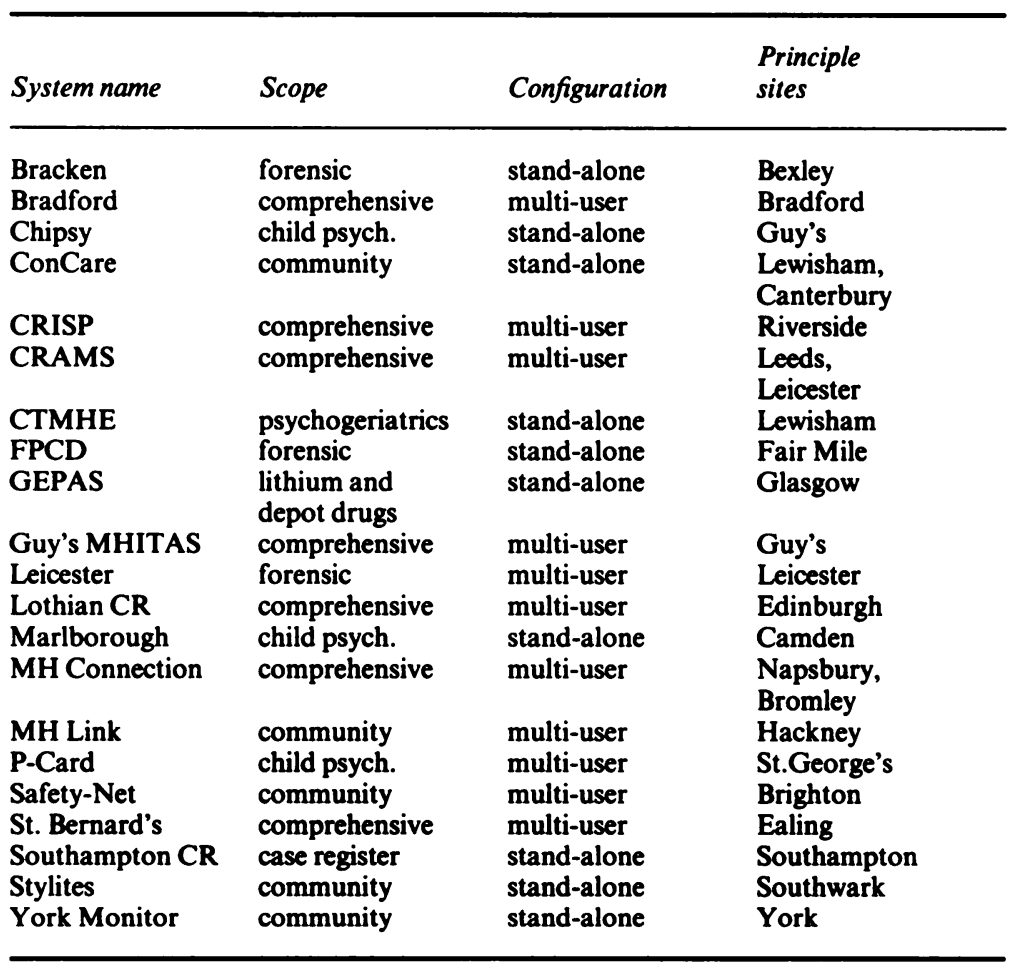


processors. Two required mini or main-frame computers. No systems were located which exclusively used non-IBM compatible micros, but one had a version for Apple Mackintosh micros. Most used hard disk storage with backup to floppy disks, but some of the larger systems also supported tape-streaming.

All seven comprehensive systems used networks to connect microcomputer terminals with the central file-serving computer, but half of the remaining simpler systems also supported multiple users, the remainder being 'stand-alone' systems which could be used by only one person at a time.

\section{Software requirements}

The MSDOS operating system was used by all but one of the registers, although two also supported Unix multi-user versions. Twelve required commercial software in addition to the operating system, usually a database management system (DBMS) such as dBase IV, RBASE or Smartware. The remaining nine systems were complete in themselves.

\section{Data structure and output}

All 21 systems stored patient details such as name, address and telephone number and also the names of workers involved. Demographic data were recorded by 19 and clinical contacts by 13. Ten provided help with Mental Health Act administration and nine could be used for the production of Korner statistics. Another ten supported records of mental states. Most catered for the entry of free text as well as categorical data.

Other features found in some systems included warnings of untoward events or loss of contact, prescription printing, life charts, discharge summaries, use of seclusion, waiting lists and appointment management.

Output was available by screen or on paper and included reports and lists with predetermined structure (all systems), user-designed reports (17), tables (18) and graphs (8).

\section{Costs}

Costs are difficult to calculate because of the need to include not only hardware and software, but also stationery and disks, maintenance, training and salaries.

A microcomputer and printer currently costs around $£ 2,000$. Database management software may cost anywhere between $£ 500$ and $£ 1,500$. Case register software ranges from absolutely free for some simple systems, to tens of thousands of pounds for comprehensive packages. At the top of the market support and maintenance is included, whereas at the bottom, the user is expected to do his own trouble-shooting.

\section{Comment}

The 21 systems surveyed have more similarities than differences: almost all run on single or networked IBM - compatible microcomputers using the MSDOS operating system. Most are inexpensive, although few are ambitious and correspondingly expensive. Most have been developed by clinicians rather than professional programmers.

The seven comprehensive systems differ in several important respects from the remaining 14 systems. Firstly, they have the potential to replace manual records, although only a few users have so far done so. The remaining 14 systems supplement rather than supplant manual records. Although this duplicates effort it can be accomplished without severe disruption of existing practice.

Clinical information systems usually received a low priority for funding in comparison to management systems and the availability of funding seemed to be inversely correlated with the amount required. Managers were disinclined to invest modest sums on clinical systems when far more could be spent on financial systems.

Computing has become an everyday adjunct to psychiatry in some parts of Britain, but in others the potential for practice, audit and research has yet to be realised. In his 1986 survey of psychiatric computing in the UK, Hedlund noted that much of the effort in the field was of an amateur nature, and he contrasted this with the situation in the United States where commercial development is the rule. Five years later, the situation is much the same but may soon begin to alter as a result of the introduction of the market to the NHS. It is to be hoped that the increased administrative burden does not result in the infanticide of clinical computing.

\section{References}

Clifford, P., Craig, T. \& Sayce, L. (eds) (1988) Towards Co-ordinated Care for People with Long-term, Severe Mental Illness. London National Unit for Psychiatric Research and Development.

Department of Health and Social Security (1988) Report of the Committee of Inquiry into the Care and After-Care of Miss Sharon Campbell. London: HMSO. Cmnd 440.

Hassall, C. (1991) The Worcester Psychiatric Case Register. The Closure of Mental Hospitals (Royal College of Psychiatrists) London: Gaskell.

HeduUND, J. L. (1986) Mental Health Computing in Great Britain. Unpublished report. St. Louis: University of Missouri. (P. Hale \& I. F. Brockington). 